\title{
Prevenção de Lesões do Ligamento Cruzado Anterior em Futebolistas*
}

\section{Prevention of Injuries of the Anterior Cruciate Ligament in Soccer Players}

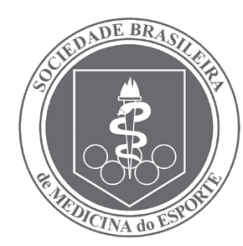

Artigo de ReVISÃo
João Brito

José Soares

António Natal Rebelo

* Faculdade de Desporto da Universidade do Porto - Porto, Portugal.

\section{Endereço para correspondência:} João Brito, Rua Dr. António Coelho, 135, $2^{\circ}$ A - 4200-079 - Porto,

Portugal.

E-mail:

joaobritofernandes@gmail.com

Submetido em 26/02/2008

Versão final recebida em 19/05/2008 Aceito em 24/10/2008

\section{RESUMO}

A lesão do joelho é a mais comum entre as lesões graves apresentadas por futebolistas, destacando-se o ligamento cruzado anterior como um dos ligamentos do joelho mais frequentemente lesados. Assim, a prevenção de lesões do ligamento cruzado anterior em futebolistas deve ser encarada como uma preocupação constante para todos os agentes ligados à modalidade, independentemente do nível competitivo, idade e sexo dos praticantes. Objetivos: O objetivo deste trabalho é a análise da importância do trabalho de prevenção de lesões do LCA em futebolistas que possa ser incorporado no treino de futebol. Metodologia: A metodologia utilizada neste trabalho foi uma revisão da literatura. Conclusões: Propõe-se um programa de prevenção de lesões do ligamento cruzado anterior em futebolistas, com três sessões de treino semanais, englobando treino neuromuscular e treino proprioceptivo.

Palavras-chave: futebol, lesão, LCA.

\section{ABSTRACT}

Knee injury is the commonest severe injury presented by football players and the anterior cruciate ligament appears as one of the most frequently injured knee ligaments. Thus, prevention of anterior cruciate ligament injuries must be a priority in soccer practice, regardless of the athletes' competitive level, age or sex. Objectives: the objective of this work is to analyze the importance of prevention of the anterior cruciate ligament injury in soccer players which can be incorporated in the training program. Methodology: the methodology used was a review of the literature. Conclusions: A program with three weekly sessions, composed by neuromuscular and proprioceptive training is proposed to prevent anterior cruciate ligament injuries in soccer players.

Keywords: soccer; prevention; injury; ACL.

\section{INTRODUÇÃO}

A popularidade do futebol tem aumentado imenso nas duas últimas décadas, estando a modalidade em constante desenvolvimento, nomeadamente no que respeita à intensidade do jogo e nível de exigência imposto aos atletas. O risco de lesão no futebol é elevado, pelo que os organismos que superintendem a modalidade têm demonstrado, cada vez mais, preocupações para com a incidência, causas e severidade das lesões no futebol moderno.

A lesão do joelho não sendo, em termos globais, a que maior incidência apresenta, é a lesão mais comum entre as lesões graves que ocorrem nos futebolistas ${ }^{(1,2)}$, destacando-se o ligamento cruzado anterior (LCA) como um dos ligamentos do joelho mais frequentemente lesados. Na literatura, os dados de natureza epidemiológica acerca das roturas do LCA, em futebolistas profissionais, são escassos ${ }^{(3)}$, pelo que a verdadeira incidência das lesões do LCA, bem como o número de atletas afetados, é difícil de determinar. No entanto, dada a incidência, severidade, custos e tempo de interrupção da atividade que acarretam, as lesões do LCA são frequentemente responsáveis pelo abandono precoce da prática desportiva e pelo surgimento de possíveis complicações na integridade e funcionalidade da articulação do joelho dos futebolistas ${ }^{(4)}$.

Desse modo, pela necessidade de se reduzir a incidência e gravidade das lesões, a prevenção de lesões do LCA em futebolistas não deve ser negligenciada nem subestimada no treino de futebolistas, independentemente do seu nível competitivo, idade e sexo, devendo a sua importância ser assumida por todos os agentes ligados à modalidade.

\section{OBJETIVOS}

O objetivo deste trabalho é a análise da importância do trabalho de prevenção de lesões do LCA em futebolistas que possa ser incorporado no treino de futebol.

\section{METODOLOGIA}

Para a realização deste trabalho foi realizada uma revisão da literatura acerca da prevenção de lesões do LCA em futebolistas. Foram utilizados artigos de periódicos indexados, bem como livros e teses de doutoramento de autores de reconhecido mérito científico, que tratassem da temática da lesão do LCA, mais concretamente no futebol.

\section{EPIDEMIOLOGIA DAS LESÕES EM FUTEBOL}

A utilização de diferentes definições e metodologias faz com que existam diversos resultados e conclusões em estudos relacionados com as lesões em futebol, dificultando assim a comparação entre os vários estudos publicados. Nesse sentido, a FIFA, através do seu Medical Assessment and Research Centre, procurou estabelecer um consenso acerca das definições, metodologia, implementação e padrões de registo que devem ser adoptados nos estudos sobre as lesões em futebol(5). Assim, uma lesão no futebol define-se como qualquer tipo de ocorrência sofrida por um jogador, em competição ou em treino, que o obrigue a interromper a sua actividade e o impeça de participar em, pelo menos, um treino ou jogo ${ }^{(5)}$. Desse modo, a classificação da gravidade da lesão baseia-se no número de dias em que o jogador se mantém afastado da actividade ${ }^{(1,4,6,7)}$ : ligeiras (um-tres dias 
de ausência), minor (três-sete dias), moderadas (seis-28 dias), major ou graves (mais de 28 dias).

Diversos investigadores estudaram a incidência e etiologia das lesões em jogadores profissionais de futebol(8), tendo-se estimando que três em cada quatro jogadores de futebol de elite sofram, por ano, uma lesão limitadora da sua performance ${ }^{(9)}$. Se a classificação das lesões assenta sobre o tempo de interrupção da actividade, é pertinente que os estudos relativos ao risco e incidência de lesões em futebol se baseiem no cálculo do número de lesões por cada 1.000 horas de jogo ou treino $(2,4,5,10,11)$. No que diz respeito à incidência lesional, verifica-se que o número de lesões que ocorre nos jogos é, em média, quatro a seis vezes superior ao número de lesões que ocorre durante as sessões de treino ${ }^{(8)}$.

Hägglund et al. ${ }^{(9)}$ compararam o tempo de prática e o risco de lesão em jogadores de elite suecos, durante as épocas de 1982 e 2001, e verificaram que, apesar de o número de jogos ter diminuído ligeiramente, o número de treinos aumentou de forma considerável (68\%), tendo daí resultado o aumento do número de lesões durante o período de treino. Os mesmos autores ${ }^{(1)}$ realizaram outro estudo prospectivo com jogadores de elite dos campeonatos dinamarquês e sueco, tendo verificado que, em ambos os países, o risco de lesão durante os jogos é superior relativamente aos treinos. A maioria das lesões registadas foi de natureza ligeira ou minor. As lesões graves cingiram-se a 9\% a 12\% do número total de lesões, sendo que a maioria das lesões (88\% e 89\%) se localizou nos membros inferiores. A coxa foi a região que apresentou maior frequência de lesões, seguida do joelho e da zona inguinal e anca.

Numa outra investigação prospectiva com jogadores de elite do campeonato sueco ${ }^{(2)}$, verificou-se também que a incidência lesional é superior nos jogos, comparativamente com os treinos, sendo que, durante o período pré-competitivo, o risco de lesão nos treinos se afigurou significativamente superior, se comparado com o período competitivo. A coxa foi a zona mais frequentemente lesionada (14\%), mas, entre as lesões graves (mais que 28 dias de ausência), a lesão do joelho foi a mais comum. O departamento médico do FC Barcelona procurou também estudar a incidência e gravidade das lesões ocorridas no clube ao longo de três anos ${ }^{(7)}$, tendo também verificado que existe maior incidência lesional nos jogos comparativamente com os treinos. Verificou-se que a zona púbica e o joelho estiveram sempre entre as zonas mais afectadas por lesão.

Um estudo realizado com a selecção nacional masculina da Suécia ${ }^{(12)}$ permitiu verificar que a incidência de lesões nos jogos em que a equipa saiu derrotada é duas vezes superior comparativamente com os jogos vencidos ou empatados. No entanto, não foram encontradas diferenças estatisticamente significativas entre as lesões ocorridas nos jogos oficiais e nos jogos amigáveis, bem como entre os jogos realizados fora de casa, em casa ou em campo neutro.

Relativamente ao risco de lesão em função do tipo de piso, não existem evidências acerca de maior risco ou severidade das lesões nos jogos e treinos decorridos em relvados artificiais comparativamente com a relva natural. A única tendência lesional que apresenta diferenças significativas entre os tipos de piso diz respeito a, em relvado artificial, ocorrer maior risco de entorse do tornozelo durante os jogos e menor risco de lesão muscular nos membros inferiores ${ }^{(6)}$.

\section{LESÃO DO JOELHO NO FUTEBOL}

O joelho, articulação intermédia do membro inferior, tem provavelmente o papel mais importante na locomoção humana ${ }^{(13)}$, pelo que se encontra exposto a diversos traumatismos, stress, lesões e doenças, que se multiplicam com a prática de actividades desportivas competiti$\operatorname{vas}^{(14)}$. No futebol, o joelho, pela sua condição de articulação altamente solicitada e exposta a traumas, é frequentemente lesado ${ }^{(15)}$. Na verdade, apesar de a coxa ser a zona de maior incidência lesional, a lesão do joelho é a mais comum entre as lesões graves dos futebolistas ${ }^{(1,2)}$.
Os gestos desportivos de base do futebol - corrida, salto, passe, remate, drible, travagem, arranque - associados à utilização de calçado desportivo com pitões, que poderão provocar alterações de aderência ao solo, sujeitam o jogador a um conjunto de macrotraumatismos e lesões de sobrecarga funcional|(16), tornando o joelho uma articulação particularmente vulnerável(10). Os futebolistas apresentam elevada incidência de diversas tendinopatias do joelho, nomeadamente ao nível do grupo flexor da articulação - "pata de ganso" e bicípite crural(16) - e do tendão rotuliano ${ }^{(17)}$. Massada ${ }^{(16)}$ apresenta ainda um estudo casuístico realizado com futebolistas profissionais, tendo registado que $11,4 \%$ das lesões se localizaram ao nível do joelho e que as entorses do joelho representaram, em termos globais, 8,8\% das lesões mais frequentes. Num outro estudo prospectivo(2), constatou-se que 39\% das lesões ligamentares apresentadas pelos futebolistas de elite suecos se localizaram no joelho, sendo que a lesão do ligamento colateral medial constituiu 54\% de todas as lesões ligamentares do joelho. Verificou-se ainda uma importante incidência de lesões meniscais.

As lesões dos ligamentos colaterais, bem como do menisco interno, resultam normalmente de tackles laterais ${ }^{(10)}$. Um estudo envolvendo jogos internacionais de torneios organizados pela FIFA permitiu concluir que o tackle lateral é a acção que mais frequentemente induz à lesão(5), o que demonstra a desadequação de algumas regras do jogo face à evidência actual dos mecanismos de lesão por falta(4), uma vez que o tackle por trás apresenta uma punição arbitral mais severa que a do tackle lateral.

Entre os futebolistas, o risco de desenvolvimento de osteoartrite no joelho é elevado ${ }^{(18)}$. Num estudo realizado com futebolistas de elite $e^{(19)}$ verificou-se elevada incidência de lesões do joelho, que frequentemente originam sintomas de osteoartrite. No entanto, verificou-se que, apesar de os atletas com lesão do joelho apresentarem elevada incidência de osteoartrite (63\%), também nos atletas sem lesão prévia o risco de desenvolvimento de osteoartrite no joelho é elevado (33\%). Não é comum a fractura da rótula em futebolistas, mas, se atingida medialmente, normalmente por um tackle alto, a rótula pode sofrer um deslocamento lateral(10).

A lesão mais grave que pode ocorrer num futebolista é aquela em que o menisco medial, o ligamento colateral medial e o ligamento cruzado anterior são agredidos simultaneamente, combinação conhecida por tríade de O'Donoghue. Nessa situação, a estabilidade da articulação fica severamente afectada ${ }^{(10)}$. No entanto, pela elevada incidência e severidade, a lesão do LCA continua a ser a lesão mais temida entre os futebolistas ${ }^{(20)}$.

\section{LESÃO DO LCA NO FUTEBOL}

O LCA é um dos ligamentos do joelho mais frequentemente lesados ${ }^{(21)}$. A lesão do LCA é um acontecimento grave que requer tratamento cirúrgico, mantendo muitos atletas afastados das competições durante, pelo menos, quatro meses da época competitiva ${ }^{(22)}$. Na maioria dos casos (70\%), se a reconstrução ligamentar for bem efectuada (e o processo de reabilitação bem conduzido), é possível que o atleta regresse à prática desportiva num nível de performance idêntico, evitando-se também o aparecimento de lesões meniscais e cartilagíneas ${ }^{(23)}$. Ainda assim, pela sua gravidade e longo período de interrupção, a lesão do LCA é, por diversas vezes, responsável pelo abandono precoce da prática desportiva e pelo surgimento de possíveis complicações na integridade e funcionalidade da articulação do joelho ${ }^{(4)}$.

Actualmente, muitos atletas, especialmente no futebol, fazem do desporto a sua actividade profissional. A maioria desses indivíduos não tem qualquer outro tipo de formação profissional, pelo que uma lesão grave pode também representar uma grande desvantagem em termos económicos ${ }^{(24)}$. Num estudo relativo aos riscos e custos das lesões do 
joelho em 12 modalidades desportivas, constatou-se que as lesões do LCA são as que acarretam custos mais elevados ${ }^{(25)}$, não apenas devido aos custos inerentes ao tratamento, mas também devido à não rentabilização do atleta, que fica impedido de exercer a actividade durante longos períodos de tempo.

Na literatura, os dados de natureza epidemiológica acerca das roturas do LCA em futebolistas profissionais são escassos ${ }^{(3)}$, o que se verifica também nos estudos relativos ao timing de início da reabilitação no terreno das lesões do LCA em futebolistas(26). É discutível o prazo decorrente entre a cirurgia de reconstrução do LCA e o reinício da prática desportiva, nomeadamente em desportos de contacto. Apesar de seis meses ser o período de tempo necessário para o regresso à prática desportiva ${ }^{(23)}$, existem casos de futebolistas que retomaram a prática competitiva apenas 120 dias após a cirurgia de reconstrução do LCA ${ }^{(26)}$.

Num estudo epidemiológico realizado com futebolistas do Campeonato Italiano Série A 2002-2003(22) observou-se incidência lesional do LCA de 0.72 lesões por 1000 horas de jogo. De forma genérica, esse valor significa que 10\% dos futebolistas italianos que participaram nesse campeonato sofreram, pelo menos, uma lesão do LCA ao longo da sua carreira desportiva. Nos jogos oficiais, o número de futebolistas afectados por lesões do LCA por contacto foi significativamente superior ao daqueles que sofreram uma lesão por não-contacto, sendo de notar que nenhuma lesão por contacto ocorreu durante jogos não oficiais ou durante os treinos, onde todas as lesões do LCA ocorreram por não-contacto.

Nas últimas décadas, o futebol feminino tem crescido de forma muito significativa ${ }^{(27)}$. Em termos epidemiológicos, a maior susceptibilidade de lesão do joelho entre as jogadoras, particularmente no que se refere à rotura do LCA, é o dado de maior importância ${ }^{(4)}$. Num estudo prospectivo realizado com futebolistas da liga de futebol feminino da Alemanha ${ }^{(29)}$, verificou-se elevada frequência de lesões do LCA, principalmente em situações de não-contacto, ao longo da época competitiva. A incidência lesional do LCA por não-contacto em jogadoras de futebol é duas a quatro vezes superior à que se verifica no futebol masculino(30,31). Pela sua elevada ocorrência, as lesões do LCA no sexo feminino representam uma relevante área de investigação da medicina desportiva ${ }^{(28)}$.

No entanto, a verdadeira incidência das lesões do LCA por nãocontacto, bem como o actual número de atletas afectados, é difícil de determinar. Para tal, seria necessário o acompanhamento de um largo número de atletas, de diferentes níveis competitivos, durante várias épocas desportivas ${ }^{(31)}$. Pela sua incidência, severidade, custos e tempo de interrupção/ausência da actividade, a prevenção de lesões do LCA em futebolistas deve ser encarada como uma preocupação constante para todos os agentes ligados à modalidade ${ }^{(32)}$, independentemente do nível competitivo, idade, sexo, condições do terreno, etc., no sentido de se reduzir não só o número de lesões, como também atenuar as suas consequências ${ }^{(4)}$.

\section{FACTORES PREDISPONENTES}

A elevada taxa de lesões observada em futebolistas merece grande preocupação por parte de todos os agentes ligados à modalidade, no sentido de se reduzir o número de lesões bem como atenuar as suas consequências(4). É consensual que prevenir é sempre melhor do que curar, pelo que a identificação da predisposição de um futebolista face às lesões é o primeiro passo a dar no sentido da sua prevenção. Não obstante, o trabalho profilático é frequentemente negligenciado, mesmo ao nível do futebol de alto rendimento ${ }^{(10)}$.

A capacidade de se direccionar e melhorar os programas de prevenção de lesões é limitada pela compreensão global da sua etiologia ${ }^{(33)}$, pelo que a elaboração e implementação de medidas preventivas requer, antes de mais, que se investigue sobre os possíveis factores de risco que podem contribuir para maior susceptibilidade do futebolista face às lesões ${ }^{(32)}$. A lesão do LCA é uma das maiores ameaças à carreira de um futebolista profissional(10), sendo que diversos factores, intrínsecos e extrínsecos, foram já investigados enquanto predisponentes da lesão do LCA por não-contacto. Ainda assim, o valor predisponente de algumas dessas variáveis continua a ser inconclusivo e discutível(32).

Existem duas grandes categorias de lesão no futebol: lesões de contacto ou acidentais - que ocorrem pela pressão exercida num determinado momento ou acção que excede os limites de resistência do tecido - e lesões de não-contacto ou sobreuso - originadas pelo excesso de stress repetido no tempo ${ }^{(4,31,34)}$. A complexa interacção entre os diversos factores dificulta o estabelecimento de estudos relativos aos factores de risco de lesão, pois é difícil englobar todos os potenciais factores de risco no mesmo estudo(27). Assim, adoptaremos a divisão tradicionalmente mais utilizada relativamente aos factores de risco de lesão: internos - relacionados com o próprio atleta - e externos - relacionados com o ambiente ${ }^{(4,31,34)}$

A lesão do LCA ocorre devido à acção de uma carga excessiva sobre o LCA, como resultado de um movimento anormal da articulação tibiofemoral que leva à falha dos suportes mecânicos que a estabilizam ${ }^{(34)}$. Devido à complexidade multifactorial(33) da lesão do LCA, procuraremos abordar de forma mais detalhada e integrada os principais factores de risco de lesão do LCA em futebolistas.

\section{FACTORES INTERNOS}

Os factores internos são características físicas e psicológicas que distinguem os indivíduos dos seus pares ${ }^{(35)}$. Verifica-se que a maioria dos futebolistas tendem a mostrar-se relutantes perante a evidência de que determinados factores internos são responsáveis pela ocorrência de lesão, afirmando que $50 \%$ das suas lesões dependem do acaso(10).

\section{Idade}

A rotura isolada do LCA ocorre com elevada frequência nos jovens desportistas, com idades compreendidas entre os 20 e os 30 anos, sendo bilateral em cerca de $20 \%$ dos $\operatorname{casos}^{(23)}$. Num trabalho relativo à prevalência de lesões do LCA em futebolistas profissionais italianos ${ }^{(22)}$ verificou-se que os indivíduos mais velhos registaram maior número de lesões do LCA. Este facto poderá ser explicado pela maior participação em jogos por parte dos futebolistas mais velhos, estando assim mais expostos à lesão. Por outro lado, os dados do estudo parecem indicar que os futebolistas que haviam sofrido uma intervenção cirúrgica do LCA enquanto jovens (20,3 $\pm 2,1$ anos) apresentavam maior risco de recorrência de lesão. No entanto, os mesmos autores ${ }^{(3)}$ referem que, de forma isolada, a idade dos futebolistas e a sua experiência no campeonato da Serie A não devem ser consideradas como factores de risco de lesão do LCA.

Nas crianças, o LCA é mais resistente do que a zona de inserção tibial, pelo que ocorrem mais casos de arrancamento da espinha da tíbia do que de rotura do ligamento ${ }^{(23)}$. Na verdade, se exceptuarmos as raparigas praticantes de futebol, onde a rotura do LCA não é uma raridade ${ }^{(30)}$, a rotura do LCA não é comum em jovens com idade inferior a 14 anos $^{(23)}$, não existindo evidências na literatura acerca da existência de diferenças nas taxas de incidência de lesão do LCA entre atletas masculinos e femininos em idades pré-pubertárias ${ }^{(36)}$.

\section{Sexo}

Em termos globais, não existem diferenças relevantes entre o futebol masculino e feminino no que respeita à incidência de lesões ${ }^{(4)}$. No entanto, no que à rotura do LCA diz respeito, as mulheres futebolistas apresentam risco de lesão duas vezes superior comparativamente com aquilo que se verifica no futebol masculino, destacando-se a ocorrência das lesões por não-contacto ${ }^{(30)}$. Vários factores extrínsecos e intrínsecos 
foram já identificados como possíveis factores de risco de lesão do LCA ${ }^{(37)}$, pelo que a compreensão das causas e mecanismos responsáveis por essa desproporcionada diferença entre sexos, em termos de incidência de lesão do LCA, requer atenção mais cuidada e aprofundada(38).

Do ponto de vista anatómico, verifica-se que o ângulo Q é um dos factores estruturais de lesão do joelho mais referidos na literatura. Nas mulheres, ao provocar uma alteração no alinhamento postural, poderá contribuir para a maior susceptibilidade na rotura do LCA ${ }^{(4)}$. Existe alguma controvérsia acerca do seu valor clínico ${ }^{(39)}$, uma vez que análises clínicas e trigonométricas parecem evidenciar que as diferenças observadas no ângulo Q entre homens e mulheres podem ser explicadas pelo facto de geralmente os homens serem mais altos que as mulheres. Indivíduos mais altos tendem a apresentar valores inferiores de ângulo Q, mas, relativizada a estatura, homens e mulheres parecem evidenciar semelhantes amplitudes de ângulo $Q^{(39)}$.

Em termos estruturais, as mulheres tendem a apresentar menor dimensão da chanfradura intercondiliana, o que se associa a maior susceptibilidade lesional do LCA ${ }^{(4)}$. No entanto, também nos homens há indicações que sugerem que a largura da base da chanfradura intercondiliana e a largura do côndilo femoral lateral podem ser importantes factores de risco da lesão do LCA ${ }^{(41)}$

A instabilidade articular, por aumento da laxidez ligamentar ou diminuição do controlo neuromuscular, está associada ao aumento do risco de lesão do joelho. Acontece que, durante o ciclo menstrual, a flutuação das hormonas femininas (estrogénio, progesterona e relaxina) pode influenciar a estabilidade passiva e activa do joelho das atletas, parecendo existir alguma relação entre a rotura do LCA e o ciclo menstrual|(42).

No contexto desportivo, a identificação das diferenças entre géneros ao nível da activação muscular dos membros inferiores, como resposta a potenciais forças adversas externas actuantes sobre o joelho, pode dar uma preciosa ajuda na compreensão dos mecanismos de lesão do LCA ${ }^{(42)}$. Verificou-se que em futebolistas pós-púberes existem diferenças cinéticas e cinemáticas entre sexos na forma como ocorre a recepção no solo após salto. As raparigas parecem apresentar menor controlo neuromuscular, o que pode explicar o maior risco de lesão do LCA comparativamente com o que se verifica nos rapazes ${ }^{(36)}$. Num estudo comparativo entre futebolistas de ambos os sexos ${ }^{(44)}$ verificouse que os homens utilizavam uma estratégia diferente de recepção no solo após salto, evidenciando maior varismo na articulação do joelho, o que sugere a existência de um mecanismo de adaptação na recepção no solo que evita ou minimiza a lesão do LCA entre os homens.

Nesse contexto, aponta-se que as mulheres apresentam um atraso na activação dos músculos isquiotibiais, característica que as deixa mais expostas às forças de translação actuantes sobre a tíbia, aquando da recepção no solo ou desaceleração. Quanto maior for a capacidade de activação dos músculos isquiotibiais, menor será a aceleração anterior da tíbia, o que poderá potenciar a diminuição das forças transmitidas aos ligamentos do joelho ${ }^{(43)}$

\section{ALTERAÇÕES ANATÓMICAS / ESTABILIDADE ARTI- CULAR}

Alguns desalinhamentos dos membros inferiores têm sido associados a um aumento do risco de lesão do LCA, por aumentar a tensão exercida sobre o ligamento ${ }^{(45)}$, sendo de destacar a excessiva pronação do pé, a hiperextensão do joelho e a torção externa da tíbia ${ }^{(32)}$. Os desalinhamentos do pé e da pélvis parecem contribuir para maior risco de lesão do LCA, principalmente se houver aumento da depressão do navicular e a anteversão da bacia. As diferenças entre géneros, no que respeita ao ângulo Q, parecem não se relacionar com a história de rotura do LCA, pelo que a excessiva pronação do pé parece afirmar-se como o principal desalinhamento dos membros inferiores associado à ocorrência de lesão do LCA ${ }^{(45)}$.

\section{FORÇA MÚSCULOESQUELÉTICA}

A estabilização do joelho resulta de uma complexa inter-relação entre a geometria óssea, as estruturas cápsulo-ligamentares e os músculos. Em termos de estabilização dinâmica, os músculos quadricípites e isquiotibiais assumem uma acção de controlo primário da articulação(32).

Comparados com não atletas, os futebolistas apresentam níveis de força superiores nos grupos musculares flexores e extensores, dos membros inferiores ${ }^{(46)}$. Porém, as acções específicas do futebol - corrida, salto, remate, etc. - privilegiam os músculos extensores do joelho em detrimento dos flexores, o que se reflecte normalmente num défice de força significativo dos isquiotibiais, tornando-os mais vulneráveis. Numa extensão forte e potente do joelho, os músculos posteriores da coxa assumem um papel essencial na estabilidade da articulação, sendo que uma fraqueza acentuada nesse grupo muscular poderá ter duas consequências graves: um incremento da probabilidade de rotura muscular e um aumento da instabilidade articular do joelho(4).

Num estudo realizado com futebolistas franceses de diferentes níveis competitivos ${ }^{(47)}$, verificou-se que os futebolistas de elite apresentavam níveis de força dos músculos flexores do joelho significativamente superiores aos dos futebolistas amadores, principalmente durante as acções de natureza excêntrica. Determinou-se ainda que, nos futebolistas, a força dos músculos flexores do joelho assume um papel fundamental na estabilização da articulação durante diversas tarefas do jogo, nomeadamente nas acções de natureza excêntrica, pelo que o treino de força dos membros inferiores deve ser sistemático na preparação desportiva dos futebolistas. Essa ideia é reforçada por Tsepis et al.(48), pois referem que, entre futebolistas amadores, a força dos isquiotibiais parece ser um factor discriminatório dos casos mais severos de lesão do LCA, confirmando estatisticamente a conexão entre o défice de força nos isquiotibiais e as debilidades funcionais do joelho.

Num outro estudo prospectivo, realizado com futebolistas suecas $^{(27)}$, verificou-se que todas as jogadoras que sofreram lesão do LCA durante o período do estudo apresentavam valores de força inferiores na relação isquiotibiais-quadricípites, durante a fase de activação concêntrica, no membro inferior lesado, comparativamente com o membro não lesado.

\section{AGILIDADE / COORDENAÇÃO}

Uma das principais razões para a maior susceptibilidade de lesão do LCA em mulheres prende-se com um atraso no recrutamento dos músculos posteriores da coxa, devido a uma descoordenação neuromuscular que permite um avanço anterior exagerado da tíbia, com consequente hipersolicitação do LCA e aumento do risco de rotura(4) Foram já registadas, em jovens praticantes de futebol, diferenças entre sexos na ocorrência de lesões do joelho por volta dos 12 anos de idade, o que parece estar associado ao facto de as raparigas demonstrarem diminuição do controlo neuromuscular do joelho desde o início até ao fim da puberdade. Pelo contrário, os rapazes melhoraram o controlo neuromuscular do joelho durante o mesmo período maturacional(36).

Num estudo especificamente concebido para investigar as diferenças nos tempos de resposta mioeléctrica de atletas de futebol e lacrosse de ambos os sexos ${ }^{(49)}$, verificou-se que, embora homens e mulheres apresentem modos similares de recrutamento muscular, as mulheres tendem a activar mais precocemente o quadricípites, o que faz diminuir a capacidade dos isquiotibiais para actuarem adequadamente na estabilização a articulação do joelho. De acordo com o mesmo estudo, a activação precoce do quadricípites, enquanto importante factor de risco de lesão do LCA, é ainda mera especulação, necessitando de mais estudos.

\section{HISTÓRIA DE LESÃO PRÉVIA}

Num estudo realizado com futebolistas profissionais suecos ${ }^{(2)}$, verifi- 
cou-se que 10\% das lesões do joelho ocorridas tinham carácter recorrente. Entre futebolistas profissionais italianos, constatou-se que os indivíduos que haviam sido sujeitos a uma cirurgia reconstrutiva do LCA no início da sua carreira profissional apresentavam maior risco de recidiva ${ }^{(22)}$. Tendo em conta o elevado índice de recorrência ${ }^{(4)}$ e que, na generalidade, a recidiva tende a afastar por mais tempo os atletas do treino e da competição, comparativamente com a lesão primária correspondente(2) ,é fundamental que, no processo de reabilitação após lesão, decorra tempo suficiente para a completa cicatrização dos tecidos, mesmo que o atleta pareça estar completamente recuperado do ponto de vista mecânico e funcional, e que o retorno à competição seja gradual, dando especial atenção aos sinais e sintomas de agravamento ou reaparecimento da lesão(4).

\section{FACTORES EXTERNOS}

Os factores externos dizem respeito às condições ambientais e ao modo como as actividades são desenvolvidas(35).

\section{Nível de competição}

É consensual que à medida que aumenta o nível competitivo aumenta também o risco de lesão, sendo a taxa de lesões em competição claramente superior, o que se reflectirá, naturalmente, em níveis de empenhamento diferenciados ${ }^{(4)}$. Cerca de $10 \%$ dos futebolistas que competiram no Campeonato Italiano Série A 2002-2003 haviam já sido sujeitos a uma ou mais cirurgias reconstrutivas do LCA durante a sua carreira profissional, constatando-se que a lesão do LCA ocorre com mais frequência em jogos oficiais, onde as lesões por contacto são mais frequentes. Pelo contrário, durante os treinos e jogos não oficiais, as lesões por não-contacto foram as mais frequentes ${ }^{(22)}$.

Num estudo realizado com futebolistas da liga alemã de futebol feminino ${ }^{(29)}$ verificou-se elevada incidência de lesões do LCA, notandose que todas ocorreram durante a competição. Este facto indica que a elevada prevalência de lesões do LCA no futebol feminino pode estar associada ao desenvolvimento da modalidade ao nível da dinâmica do jogo e da capacidade atlética das futebolistas.

\section{Número de jogos efectuados}

Verificou-se que, entre os futebolistas profissionais italianos, os indivíduos mais velhos registaram maior número de lesões do LCA, facto que poderá estar associado à maior participação em jogos por parte destes, estando assim mais sujeitos a contrair essa lesão(22).

\section{Calçado desportivo}

A relação entre o calçado desportivo utilizado e as lesões desportivas é ainda controversa, requerendo mais investimento e investigações mais adequadas ${ }^{(50)}$. No entanto, sabe-se que o mecanismo mais frequente de lesão do LCA se relaciona com movimentos de rotação, movimentos estes que são dificultados pela fixação dos pitões das botas de futebol ao solo. Nesse sentido, o comprimento (e tipologia) dos pitões pode constituir um factor de risco, uma vez que, ao não permitir a rotação fluída do pé no solo, pode provocar a lesão dos ligamentos do joelho(4).

\section{MECANISMOS DE LESÃO}

O joelho tem sido considerado como a articulação mais complexa do corpo humano, sendo que é nos ligamentos cruzados, principalmente no LCA, que se localiza o ponto fulcral da cinemática da articulação ${ }^{(23)}$. Um bom entendimento dos mecanismos de tensão do LCA é a base para a compreensão dos seus principais mecanismos de lesão, questão essencial para a identificação de factores de risco e desenvolvimento de estratégias de prevenção(51).

O LCA fixa-se ântero-lateralmente à espinha tibial posterior. Funde-se ligeiramente com o corno anterior do menisco lateral e corre posterior, lateral e proximalmente para se fixar na parte posterior da superfície medial do côndilo femoral lateral ${ }^{(52)}$. O LCA funciona como estabilizador em todos os movimentos de rotação e translação do joelho, mas a sua principal função estabilizadora consiste em prevenir a translação anterior da tíbia em relação ao fémur. É também um opositor à rotação interna e externa da tíbia em relação ao fémur, principalmente na extensão do joelho, e limita a deformação em valgo e varo quando em extensão(23)

Desse modo, a rotura do LCA torna a articulação do joelho instável e incapaz de controlar forças inerentes a actividades físicas intensas, pelo que, mesmo com intensa reabilitação, a realização de movimentos de rápida desaceleração, mudanças de direcção e recepção no solo a um apoio (típicos no futebol) tornam-se impossíveis. O tratamento não dispensa normalmente a reconstrução cirúrgica do LCA lesado, sendo necessário um prolongado período de reabilitação física para que o atleta possa retomar os níveis de actividade física normais ${ }^{(53)}$.

No futebol, a lesão do LCA é bastante comum, ocorrendo normalmente por mecanismos de não-contacto ${ }^{(51)}$. Os indivíduos referem frequentemente ter sentido algo a "estourar" dentro do joelho, o que corresponde ao ultrapassar do limiar da resistência das fibras do LCA. Muitas vezes, é referido ainda que o joelho "saiu do lugar", manifestação de subluxação fémoro-tibial. Alguns minutos após a rotura, surge um derrame sanguíneo mais ou menos volumoso ${ }^{(23)}$. A maioria das lesões do LCA ocorre com flexão do joelho entre $0^{\circ}$ e $30^{\circ}$, normalmente em situações de não-contacto, em corrida ou em salto ${ }^{(54)}$, gerando-se grande tensão sobre o LCA, através da leve flexão, varo e rotação externa do fémur ${ }^{(23)}$. Mais raramente, o LCA pode romper quando o joelho está em flexão, valgo e rotação interna do fémur ${ }^{(23)}$.

Na corrida, os movimentos que têm estado associados à lesão incluem mudança de direcção, rápida desaceleração, paragem espontânea e movimentos de torção. No salto, os movimentos correspondem à recepção no solo em varo e rotação interna ou em valgo e rotação externa ${ }^{(55)}$. Os mecanismos de lesão por não-contacto são similares em homens e mulheres ${ }^{(31)}$.

A rotura isolada do LCA, parcial ou total, pode também ocorrer em hiper-extensão, por conflito com o tecto da chanfradura intercondiliana, quando esta apresenta dimensão inferior à normal. A coexistência de recurvatum propicia a rotura ligamentar, principalmente se associada à contractura quadricipital, causando subluxação anterior da tíbia(23).

Embora possa ser importante uma detalhada descrição biomecânica, esse tipo de abordagem nem sempre é suficiente quando se pretende desenvolver medidas preventivas efectivas ${ }^{(56)}$, até porque não parecem existir evidências na literatura de que o varismo/valgismo e a rotação interna/externa do joelho sejam, por si sós, responsáveis pelas lesões do LCA por não-contacto ${ }^{(51)}$. A capacidade de desenvolver programas preventivos, através do treino e de outro tipo de medidas profilácticas, é limitada pela incompleta compreensão das causas das lesões, pelo que, se se pretende promover todo o potencial preventivo de um programa, a informação relativa aos mecanismos de lesão deve ser relacionada com o modo como os factores de risco internos e externos influenciam o risco de lesão(3) ${ }^{(33)}$ Sem o completo entendimento dos mecanismos de lesão, os factores de risco de lesão do LCA podem ser mal interpretados, levando à selecção de programas de prevenção desadequados ${ }^{(51)}$.

\section{PREVENÇÃO DE LESÃO DO LCA EM FUTEBOLISTAS}

No que se refere especificamente às lesões do joelho no futebol, parecem existir evidências de que o treino proprioceptivo e o treino neuromuscular podem prevenir o aparecimento desse tipo de lesões ${ }^{(8,57-59)}$. Tal facto impõe a necessidade de se implementarem programas específicos de condicionamento, educação e treino dedicados à prevenção de lesões do LCA, promovendo maior controlo corporal durante a actividade desportiva ${ }^{(60)}$ 


\section{Treino neuromuscular}

O treino neuromuscular visa o aumento das respostas motoras involuntárias através da simulação de sinais aferentes e dos mecanismos centrais responsáveis pelo controlo articular dinâmico. Tem por objetivos a melhoria da habilidade do sistema nervoso para gerar padrões rápidos e ideais de resposta muscular, aumento da estabilidade articular, diminuição das forças articulares e recuperação de padrões de movimento e habilidades ${ }^{(61)}$. As componentes do treino neuromuscular incluem o desenvolvimento da força muscular - resistência de força e potência ${ }^{(4,62)}$, melhoria dos mecanismos de activação neuromuscular e aquisição de skills específicos da modalidade ${ }^{(57-59)}$. Apesar de existirem evidências dos benefícios do treino neuromuscular ao nível da redução do risco de lesões, se os programas de treino não forem direccionados para a melhoria da performance, os atletas poderão não se mostrar motivados para a participação em programas de treino neuromuscular ${ }^{(62)}$

O treino da força é vital em qualquer programa de prevenção de lesões, pois é elemento base da velocidade, da potência e do controlo corporal ${ }^{(60,63)}$. Nem sempre é possível encontrar uma relação directa entre a força muscular e a performance do futebolista, mas sabe-se que as acções específicas do jogo - arranques, travagens, saltos, remates, mudanças de direcção rápidas, entre outras - necessitam de elevados níveis de força para se expressar ${ }^{(64)}$. Os objetivos gerais do treino da força em futebolistas prendem-se com o aumento da potência muscular durante as fases altamente intensas do jogo, diminuição da perda de força atribuível à fadiga ao longo do jogo, recuperação rápida dos níveis de força após jogo ou treino e prevenção de lesões ${ }^{(64)}$. De forma geral, a força é dividida em força máxima, resistência de força e potência ${ }^{(4)}$. No entanto, dadas as características do futebol, o treino da força máxima não é um tipo de treino que se adapte às características específicas dos futebolistas ${ }^{(64)}$.

No futebol, a força dos músculos isquiotibiais, pela acção frenadora que exercem sobre o deslizamento anterior da tíbia, assume uma importância vital na estabilização do joelho, principalmente nas acções de natureza excêntrica ${ }^{(47)}$. Não obstante, as acções específicas do futebol privilegiam os músculos extensores do joelho em detrimento dos flexores, o que se reflecte, normalmente, num défice de força significativo dos isquiotibiais, tornando-os mais vulneráveis ${ }^{(4)}$. Num estudo realizado com futebolistas franceses de diferentes níveis competitivos ${ }^{(47)}$ verificou-se que os futebolistas de elite apresentaram uma relação quadricípites/isquiotibiais superior, resultante de maior torque excêntrico ao nível dos isquiotibiais, o que sugere que a força excêntrica do grupo muscular flexor do joelho é facilmente treinável. Por outro lado, outro estudo ${ }^{(65)}$ revelou que os futebolistas de elite e amadores não parecem apresentar assimetrias musculares nos grupos musculares extensores e flexores do joelho, concluindo-se daqui que a exposição a treinos e jogos durante vários anos pode desenvolver, nos futebolistas, níveis máximos de força e potência nos membros inferiores.

Sabe-se que a relação isquiotibiais/quadricípites deve situar-se entre 55 e $60 \%{ }^{(4)}$ e que, no que respeita à força muscular, esta relação parece ser o único factor discriminatório relativamente aos casos mais severos de lesão do LCA ${ }^{(48)}$. Se forem verificados desequilíbrios nos grupos musculares flexores e extensores do joelho, aconselha-se o estabelecimento de programas personalizados de treino de força, que podem incorporar exercícios específicos de reabilitação ${ }^{(65)}$. É de registar ainda que há indicações de que, em indivíduos com deficiente estabilização articular, os flexores plantares do tornozelo podem contribuir na estabilização do joelho. Esse facto sugere que o músculo gastrocnémio actua na estabilização articular dinâmica do joelho, o que deverá ser enfatizado nos programas de prevenção(61).
Ainda assim, é frequente ver futebolistas que, apesar das suas competências específicas no jogo, apresentam debilidade muscular generalizada. Se por um lado pode defender-se que uma estrutura muscular mais desenvolvida poderia beneficiar o seu desempenho, há que ter consciência de que o treino pode, na realidade, ser prejudicial para o desempenho do futebolista. Assim, caso sejam detectados sinais evidentes de inadaptação ao tipo de trabalho que o futebolista está a efectuar, o processo deve ser imediatamente interrompido, admitindose que, neste caso específico, a estrutura desse futebolista não pode ser alterada, sob pena de se ver prejudicada a sua competência(64).

Em termos de treino neuromuscular há ainda que ter em atenção o facto de, principalmente entre as mulheres, poder ocorrer um atraso no recrutamento dos músculos posteriores da coxa, que se reflecte numa descoordenação neuromuscular que aumenta o risco de rotura do LCA ${ }^{(4)}$. Apesar de os dados relativos à activação precoce dos isquiotibiais, enquanto factor de risco de lesão do LCA, serem meramente especulativos ${ }^{(49)}$, sugere-se que se invista nos possíveis benefícios do treino de coordenação dos membros inferiores como forma de diminuição do risco de lesão ligamentar ${ }^{(38)}$.

\section{Treino proprioceptivo}

A propriocepção diz respeito às informações e mecanismos que contribuem para o controlo postural, estabilidade articular e para diversas sensações conscientes ${ }^{(66)}$. As estruturas base dessa capacidade designam-se por proprioceptores e desempenham um papel determinante na capacidade de o atleta efectuar de forma segura, eficiente e tecnicamente ajustada os diferentes gestos desportivos ${ }^{(4)}$. Os proprioceptores localizam-se primariamente nos músculos, tendões, ligamentos e cápsulas articulares, sendo que aqueles que se encontram nas camadas profundas da pele e nas fáscias musculares associam-se, normalmente, apenas a sensações tácteis(66).

O controlo neuromuscular assume uma importância fundamental no futebol, visto que a estabilização dinâmica das estruturas corporais decorre preferencialmente em apoio unipodal, sendo as habilidades executadas com o membro inferior contralateral. Na verdade, as exigências do jogo de futebol incluem acções repetidas de controlo excêntrico e de estabilização dinâmica do membro inferior durante o remate, mudanças de direcção muito rápidas e espontâneas e acções imprevisíveis de apoio dos pés no solo. Estes factores, associados ao facto de o futebol ser um desporto de contacto, requerem nos futebolistas informações proprioceptivas relevantes, provenientes dos receptores sensitivos aferentes, de modo que o controlo neuromuscular seja ajustado não só à performance das habilidades mas também ao não aparecimento de lesões ${ }^{(68)}$.

O LCA possui diferentes tipos de terminações sensitivas: corpúsculos de Ruffini, responsáveis pela adaptação do ligamento a estímulos suaves; corpúsculos de Pacini, que garantem a resposta do ligamento a estímulos bruscos; e corpúsculos de Golgi, responsáveis pela resposta a estímulos externos, tais como traumatismos intensos, que põem o joelho em posição de extrema estabilidade. Na verdade, os receptores e as terminações nervosas ocupam cerca de $1 \%$ do volume do LCA ${ }^{(69)}$, pelo que, quando este ligamento é colocado sob elevado stress, os proprioceptores respondem como forma de protecção à integridade mecânica ${ }^{(4)}$.

Verificou-se que indivíduos com lesão do LCA podem desenvolver modelos de adaptação motora que envolvem o aumento da activação dos isquiotibiais antes de a articulação estar em carga, mantendo o joelho numa posição de maior flexão durante a carga. Essas alterações, ocorridas na ausência do LCA, previnem a translação anterior da tíbia, uma vez que o aumento da activação dos isquiotibiais ocorre antes de a articulação estar em carga, num mecanismo de controlo por feedforward, sugerindo que o controlo motor pode processar-se a nível reflexo ${ }^{(67)}$. 
É interessante verificar também que há indivíduos com acentuada laxidez ligamentar por rotura do LCA que conseguem praticar desporto de alto rendimento, desde que usem uma vulgar joelheira, uma vez que a simples compressão cutânea assim obtida parece reactivar os receptores de superfície, tornando normal o padrão de recrutamento muscular. Desse modo, a educação proprioceptiva apresenta um papel fundamental na estabilização do joelho(69).

O treino proprioceptivo tem vindo a assumir um papel decisivo como factor integrante dos programas de prevenção de lesões no futebol. Os exercícios baseiam-se em situações onde a variabilidade e a instabilidade são dois factores constantes, pelo que se sugere que decorram em superfícies móveis, com diferentes graus de dureza, com apoio unipodal e ainda com e sem referências visuais ${ }^{(4)}$.

\section{CONCLUSÕES}

\section{Avaliação do risco de lesão do LCA}

Existem procedimentos de avaliação que quantificam de forma rigorosa insuficiências ou discrepâncias estruturais que o atleta possa apresentar. No entanto, nem sempre existe disponibilidade de meios para a realização desses testes específicos. Desse modo, propomos um conjunto de testes simples que permitem a detecção de alguns factores de risco de lesão do LCA (tabela 1). Apesar de não predizerem com total garantia se o atleta apresenta risco de lesão, esses procedimentos poderão dar indicações específicas acerca da necessidade de se intervir preventivamente ${ }^{(4,60)}$

Tabela 1. Procedimentos de avaliação do risco de lesão do $\operatorname{LC}(4,60)$

\begin{tabular}{l|l}
\hline $\begin{array}{c}\text { Avaliação } \\
\text { postural do } \\
\text { joelho }\end{array}$ & $\begin{array}{l}\text { A avaliação dos joelhos deverá ter em consideração as } \\
\text { três alterações mais frequentes: joelhos varum, valgus e } \\
\text { recurvatum. }\end{array}$ \\
\hline $\begin{array}{l}\text { Teste de } \\
\text { squat com } \\
\text { apoio } \\
\text { bipodal }\end{array}$ & $\begin{array}{l}\text { De pé, o atleta eleva ambos os braços acima da cabeça. Realiza } \\
\text { flexão dos joelhos até } 90^{\circ} \text {, pára na posição e retorna à posição } \\
\text { inicial. Se os joelhos se mantiverem alinhados com os pés, o atleta } \\
\text { não deverá apresentar desalinhamento estrutural do joelho. Se os } \\
\text { joelhos se desviarem medialmente em relação aos pés, o atleta } \\
\text { deverá apresentar valgismo. Quanto maior for esse desvio, maior } \\
\text { será o risco de lesão do LCA. O observador deve posicionar-se de } \\
\text { frente para o atleta, visualizando a posição dos joelhos durante a } \\
\text { fase de flexão. Adicionalmente, poderá posicionar-se lateralmente, } \\
\text { verificando se os joelhos avançam em relação aos pés, situação que } \\
\text { poderá expor o joelho a uma carga excessiva. }\end{array}$
\end{tabular}

Teste de squat com apoio unipodal
De pé, apoiado apenas num membro inferior (MI), o atleta realiza flexão do joelho até $90^{\circ}$, sem ajuda dos membros superiores, pára na posição e retorna à posição inicial. Posteriormente, executa o mesmo procedimento sobre o membro contralateral. O observador deve atentar novamente sobre o valgismo do joelho, bem como sobre o grau de dificuldade do atleta em controlar o movimento desde o início até ao fim, pois este é um bom indicador da força funcional do atleta. Se houver grandes diferenças no controlo corporal na fase descendente, é possível que existam desequilíbrios musculares entre os membros.

Análise da recepção ao solo após salto

\section{Proposta de programa de prevenção de lesão do LCA em futebolistas}

O programa de prevenção de lesões do LCA em futebolistas proposto (tabela 2) engloba treino neuromuscular e treino proprioceptivo, procurando enfatizar sempre a adopção da técnica ajustada na execução das habilidades ${ }^{(70)}$.

O programa deverá ter pelo menos seis a 12 semanas de duração, podendo decorrer durante toda a época competitiva ${ }^{(36,60,62,71)}$. Deverá ser composto por três sessões de treino por semana, com duração de 15 a 30 minutos por sessão(59,71).

Antes de cada sessão de treino, propõe-se a realização de um aquecimento dinâmico ${ }^{(60,62)}$, que incorpore movimentos específicos da modalidade, realizados a baixa intensidade para melhor preparar o organismo para as exigências do treino ${ }^{(60,72)}$.

Tabela 2. Programa de prevenção de lesões do LCA em futebolistas

\begin{tabular}{|c|c|c|}
\hline & & $\begin{array}{c}\text { Princípios } \\
\text { metodológicos }\end{array}$ \\
\hline \multicolumn{3}{|l|}{ 1. Aquecimento } \\
\hline & $\begin{array}{l}\text { - Jogging frontal e à retaguarda } \\
\text { - Corrida lateral } \\
\text { - Corrida com passo cruzado } \\
\text { - Marcha com elevação de Ml à frente } \\
\text { - Skipping baixo/alto } \\
\text { - Balanços laterais e frontais de Ml } \\
\text { - Marcha com diferentes tipos de apoio do } \\
\text { pé no solo }\end{array}$ & $\begin{array}{l}\text { Distância: 10-20m } \\
\text { Repetições: } 2\end{array}$ \\
\hline \multicolumn{3}{|c|}{ 2. Treino neuromuscular } \\
\hline Potência & $\begin{array}{l}\text { - Impulsões horizontais consecutivas com } \\
\text { Ml unidos } \\
\text { - Impulsões verticais com rotação de } 180^{\circ} \\
\text { - Hops frontais consecutivos } \\
\text { - Hops laterais consecutivos }\end{array}$ & $\begin{array}{l}\text { Duração: 4"-8" } \\
\text { Velocidade: máxima } \\
\text { Repetições: 4-6 } \\
\text { Séries: } 2-4 \\
\text { Intervalo: 1'30"-2' }\end{array}$ \\
\hline $\begin{array}{l}\text { Activação } \\
\text { neuromuscular }\end{array}$ & $\begin{array}{l}\text { - Partidas frontais em queda facial } \\
\text { - Partidas de costas e de lado }\end{array}$ & $\begin{array}{l}\text { Velocidade: máxima } \\
\text { Duração: } 2^{\prime \prime}-10^{\prime \prime} \\
\text { Repetições: } 2-8 \\
\text { Series: } 1-3 \\
\text { Intervalo: } 5 \text { x duração }\end{array}$ \\
\hline $\begin{array}{l}\text { Resistência } \\
\text { de força }\end{array}$ & $\begin{array}{l}\text { - Afundos multidireccionais } \\
\text { - Russian hamstring }\end{array}$ & $\begin{array}{l}\text { Duração: } 20^{\prime \prime}-45^{\prime \prime} \\
\text { Velocidade: média } \\
\text { Repetições: 8-12 } \\
\text { Séries: 2-4 } \\
\text { Intervalo: 1'-1'30" }\end{array}$ \\
\hline \multicolumn{3}{|c|}{ 3. Treino proprioceptivo } \\
\hline & $\begin{array}{l}\text { - Equilíbrio unipodal com desequilíbrios } \\
\text { provocados por ajudante } \\
\text { - Equilíbrio unipodal com execução de ha- } \\
\text { bilidade com bola } \\
\text { - Equilíbrio unipodal com flexão e inclina- } \\
\text { ção lateral do tronco }\end{array}$ & $\begin{array}{l}\text { Duração: } 30^{\prime \prime} \\
\text { Repetições: } 2 \text { (cada } \\
\text { membro inferior) }\end{array}$ \\
\hline
\end{tabular}

Deve ter-se em atenção que poderá ser necessário promover modificações específicas em alguns exercícios em função da idade, sexo, indicação médica e/ou experiência de treino do atleta ${ }^{(60)}$.

É de notar que nenhum dos exercícios propostos requer qualquer tipo de equipamento sofisticado, tais como máquinas de musculação ou material dispendioso, de modo que este programa de prevenção de lesões do LCA pode ser utilizado no treino de qualquer equipa de futebol.

Todos os autores declararam não haver qualquer potencial conflito de interesses referente a este artigo. 


\section{REFERÊNCIAS BIBLIOGRÁFICAS}

1. Hägglund M, Waldén M, Bahr R, Ekstrand J. Methods for epidemiological study of injuries to professional football players: developing the UEFA model. BR J Sports Med. 2005;39(6):340-6.

2. Waldén $M$, Hägglund M, Ekstrand J. Injuries in Swedish elite football - a prospective study on injury definitions, risk for injury and injury pattern during 2001. Scand J Med Sci Sports. 2005;15(2):118-25.

3. Roi GS, Nanni G, Tavana R, Tencone F. Epidemiology of anterior cruciate ligament ruptures in First League soccer players. J Sports Sci. 2004;22(6):591.

4. Soares J. O treino do futebolista. Lesões - Nutrição. Porto: Porto Editora; 2007.

5. Fuller CW, Ekstrand J, Junge A, Andersen TE, Bahr R, Dvorak J, et al. Consensus statement on injury definitions and data collection procedures in studies of football (soccer) injuries. Scand J Med Sc Sports. 2006;16(2):83-92

6. Ekstrand J, Timpka T, Hägglund M. Risk of injury in elite football played on artificial turf versus natura grass: a prospective two-cohort study. Br J Sports Med. 2006;40(12):975-80

7. Rodas G, Til L, Medina D, Solé J, Ardèvol J. Prevención de lesiones en el fútbol. In: Editorial Q, editor. XVI Jornadas Internacionales de Traumatología del Deporte. $1^{\text {a }}$ ed. Murcia: Asociación Murciana de Medicina del Deporte. 2006:51-62.

8. Junge A, Dvorak J. Soccer injuries: a review on incidence and prevention. Sports Med. 2004:34(13):92938. Review.

9. Hägglund $M$, Waldén $M$, Ekstrand J. Exposure and injury risk in Swedish elite football: a comparison between seasons 1982 and 2001. Scandinavian Journal of Medicine and Science in Sports 2003;13:364-70

10. Reilley T, Howe T. Injury prevention and rehabilitation. In: Reilley T, editor. Science and Soccer. London: E \& FN Spon; 1996. p. 151-64

11. Hägglund $M$, Waldén $M$, Ekstrand J. Injury incidence and distribution in elite football - a prospective study of the Danish and the Swedish top divisions. Scand J Med Sci Sports. 2005;15(1):21-8,

12. Ekstrand J, Waldén M, Hägglund M. Risk for injury when playing in a national football team. Scand J Med Sci Sports. 2004;14(1):34-8.

13. Silva MVd. Anatomia do joelho. In: Espregueira-Mendes J, Pessoa P, editors. O Joelho. Lousã: Lidel - Edições Técnicas, Lda; 2006. p. 1-22.

14. Caillet R. Dor no Joelho. 3a ed. Porto Alegre, RS: Artmed Editora Ltda; 2001

15. Stewien ETdM, Camargo OPAd. Ocorrência de entorse e lesões do joelho em jogadores de futebol da cidade de Manaus, Amazonas. Acta Ortop Bras. 2005;13(3):141-6.

16. Massada L. Lesões típicas do desportista. 3a ed. Lisboa: Editorial Caminho, SA; 2000.

17. Fredberg $U$, Bolvig L. Significance of ultrasonographically detected asymptomatic tendinosis in the patellar and achilles tendons of elite soccer players: a longitudinal study. Am J Sports Med. 2002;30(4):488-91.

18. Sandmark H, Vingard E. Sports and risk for severe osteoarthrosis of the knee. Scand J Med Sci Sports. 1999;9(5):279-84

19. Larsen E, Jansen PK, Jensen PR. Long-term outcome of knee and ankle injuries in elite football. Scand J Med Sci Sports. 1999:9(5):285-9.

20. Boone J. Addressing the ACL. Ways to help prevent soccer's most dreaded injury. Soccer Journal. 2006;15:36-7.

21. Boden BP, Griffin LY, Jr. WEG. Etiology and Prevention of Noncontact ACL Injury. Phys Sportsmed. 2000;28(4).

22. Roi GS, Nanni G, Tavana R, Tencone F. Prevalence of anterior cruciate ligament reconstructions in professional soccer players. Sports Science for Heath. 2006;1:118-21.

23. Noronha JC. Lesões do ligamento cruzado anterior. In: Espregueira-Mendes J, Pessoa P, editors. O Joelho. Lisboa: Lidel - edições técnicas, Ida; 2006. p. 147-82

24. Forssblad M, Weidenhielm L, Werner S. Knee surgery costs in football, floor ball, European team handball and ice hockey. Scand J Med Sci Sports. 2005;15(1):43-7.

25. De Löes M, Dahlstedt LJ, Thomée R. A 7-year study on risks and costs of knee injuries in male and female youth participants in 12 sports. Scand J Med Sci Sports. 2000;10(2):90-7.

26. Tencone F, Berti L, Roi S. On-field rehabilitation for accelerated return to competitive soccer after anterior cruciate ligament reconstruction. J Sports Sci. 2004;22(6).

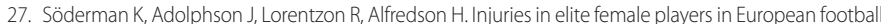
a prospective study over one outdoor soccer season. Scand J Med Sci Sports. 2001;11(5):299-304.

28. Grandstrand SL, Pfeiffer RP, Sabick MB, DeBeliso M, Shea KG. The effects of a commercially available warm-up program on landing mechanics in female youth soccer players. J Strength Cond Res 2006;20(2):331-5

29. Faude O, Junge A, Kindermann W, Dvorak J. Injuries in female soccer players: a prospective study in the German national league. Am J Sports Med. 2005;33(11):1694-700.

30. Arendt E, Dick R. Knee injury patterns among men and women in collegiate basketball and soccer: NCAA data and review of literature. Am J Sports Med. 1995:23(6):694-701.

31. Ireland ML. Anterior Cruciate Ligament Injury in Female Athletes: Epidemiology. J Athl Train. 1999;34(2):150-4.

32. Bonci CM. Assessment and Evaluation of Predisposing Factors to Anterior Cruciate Ligament Injury J Athl Train. 1999:34(2):155-64

33. Bahr R, Krosshaug T. Understanding injury mechanisms: a key component of preventing injuries in sport. Br J Sports Med. 2005:39(6):324-9.

34. Hughes G, Watkins J. A Risk-Factor Model for Anterior Cruciate Ligament Injury. Sports Med. 2004:36(5):411-28

35. Griffin LY, Agel J, Albohm MJ, Arendt EA, Dick RW, Garrett WE, et al. Noncontact anterior cruciate ligament injuries: risk factors and prevention strategies. J Am Acad Orthop Surg. 2000;8(3):141-50.

36. Hewett TE, Myer GD, Ford KR. Decrease in neuromuscular control about the knee with maturation in female athletes. J Bone Joint Surg. 2004;86-A(8):1601-8

37. Bowerman SJ, Smith DR, Carlson M, King GA. A comparison of factors influencing ACL injury in male and female athletes and non-athletes. Phys Ther Sport. 2006;7(3):144-52
38. Pollard CD, Heiderscheit BC, van Emmerik RE, Hamill J. Gender differences in lower extremity coupling variability during an unanticipated cutting maneuver. J Appl Biomech. 2005;21(2):143-52.

39. Grelsamer RP, Dubey A, Weinstein CH. Men and women have similar $\mathrm{Q}$ angles. A clinical and trigonometric evaluation. J Bone Joint Surg. 2005;87-B(11):1498-501.

40. Horton M, Hall T. Quadriceps femoris muscle angle: normal values and relationships with gender and selected skeletal measures. Phys Ther. 1989;69(11):897-901.

41. Angelo RdCdO, Moraes SRAd, Suruagy LC, Tashiro T, Costa HM. Estudo morfométrico da fossa intercondilar femoral em joelhos com e sem lesão do ligamento cruzado anterior (L.C.A.), através da aplicação de um software sobre imagens radiográficas digitalizadas. Acta Ortop Bras. 2004;12(3):146-54.

42. Hewett T. Neuromuscular and hormonal factors associated with knee injuries in female athletes Strategies for intervention. Sports Med. 2000;29(5):313-27.

43. Garrison JC, Hart JM, Palmieri RM, Kerrigan DC, Ingersoll CD. Lower Extremity EMG in Male and Female College Soccer Players During Single-Leg Landing. J Sport Rehabil. 2005;14:48-57.

44. Garrison JC, Hart JM, Palmieri RM, Kerrigan DC, Ingersoll CD. Comparison of knee-joint moments in male and female college soccer players during a single-leg landing. J Sport Rehabil. 2005;14:332-7.

45. Hertel J, Dorfman JH, Braham RA. Lower extremity malalignments and anterior cruciate ligament injury history. J Sports Sci Med. 2004;3:220-5

46. Ergün M, Islegen C, Taskiran E. A cross-sectional analysis of sagittal knee laxity and isokinetic muscle strength in soccer players. Int J Sports Med. 2004;25(8):594-8.

47. Cometti G, Maffiuletti NA, Pousson M, Chatard JC, Maffulli N. Isokinetic strength and anaerobic power of elite, subelite and amateur French soccer players. Int J Sports Med. 2001;22(1):45-51.

48. Tsepis E, Vagenas G, Giakas G, Georgoulis A. Hamstring weakness as an indicator of poor knee function in ACL-deficient patients. Knee Surg Sports Traumatol Arthrosc. 2004;12(1):22-9.

49. Shultz SJ, Perrin DH, Adams MJ, Arnold BL, Gansneder BM, Granata KP. Neuromuscular Response Characteristics in Men and Women After Knee Perturbation in a Single-Leg, Weight-Bearing Stance. J Athl Train. 2001;36(1):37-43.

50. Murphy DF, Connolly DA, Beynnon BD. Risk factors for lower extremity injury: a review of the literature. Br J Sports Med. 2003;37(1):13-29.

51. Yu B, Garrett WE. Mechanisms of non-contact ACL injuries. Br J Sports Med. 2007;41Suppl 1:i47-51.

52. Palastanga N, Field D, Soames R. Anatomia e Movimento Humano: Estrutura e Função. $3^{a}$ ed. São Paulo: Editora Manole; 2000

53. Perrin DH, Shultz SJ. Physical rehabilitation and the challenge of anterior cruciate ligament injury in the physically active female. QUEST. 2005:57:154-61.

54. Boden BP, Griffin LY, Jr. WEG. Etiology and prevention of noncontact ACL injury. Phys Sportsmed. 2000;28(4).

55. Cerulli G, Benoit DL, Lamontagne M, Caraffa A, Liti A. In vivo anterior cruciate ligament strain behaviour during a rapid deceleration movement: case report. Knee Surg Sports Traumatol ArthrosC 2003;11(5):307-11

56. Krosshaug T, Andersen TE, Olsen OE, Myklebust G, Bahr R. Research approaches to describe the mechanisms of injuries in sport: limitations and possibilities. Br J Sports Med. 2005;39(6):330-9.

57. Myer GD, Ford KR, Brent JL, Hewett TE. The effects of plyometric vs. dynamic stabilization and balance training on power, balance, and landing force in female athletes. J Strength Cond Res. 2006;20(2):345-53

58. Owen JL, Campbell S, Falkner SJ, Bialkowski C, Ward AT. Clinical question: Is there evidence that proprioception or balance training con prevent anterior cruciate ligament $(\mathrm{ACL})$ injuries in athletes without previous ACL injury? Phys Ther. 2006;86(10):1436-40.

59. Mandelbaum BR, Silvers HJ, Watanabe DS, Knarr JF, Thomas SD, Griffin LY, et al. Effectiveness of a neuromuscular and proprioceptive training program in preventing anterior cruciate ligament injuries in female athletes: 2-year follow-up. Am J Sports Med. 2005:33(7):1003-10.

60. Schiff B, Smith B. Protecting the Athlets's Knee. A Complete Guide to ACL Injury Preventon and Athletic Excellence: PTAK: 2004

61. Risberg MA, Mork M, Jenssen HK, Holm I. Design and implementation of a neuromuscular training program following anterior cruciate ligament reconstruction. J Orthop Sports Phys Ther. 2001;31(11):620-31

62. Myer GD, Ford KR, Palumbo JP, Hewett TE. Neuromuscular training improves permormance and lower-extremity biomechanics in female athletes. J Strength Cond Res. 2005;19(1):51-60.

63. Pfeiffer RP, Shea KG, Roberts D, Grandstrand S, Bond L. Lack of effect of a knee ligament injury prevention program on the incidence of noncontact anterior cruciate ligament injury. J Bone Joint Surg Am. 2006:88(8):1769-74.

64. Soares J. O treino do futebolista. Porto: Porto Editora, Ida; 2005.

65. Christos G, Athanasios Z, George D, Nikolaos Z. Bilateral Peak Torque of the Knee Extensor and Flexo Muscles in Elite and Amateur Male Soccer Players. Physical Training; 2005.

66. Riemann BL, Lephart SM. The Sensorimotor System, Part I: The Physiologic Basis of Functional Joint Stability. J Athl Train. 2002:37(1):71-9.

67. Riemann BL, Lephart SM. The Sensorimotor System, Part Il: The Role of Proprioception in Motor Control and Functional Joint Stability. J Athl Train. 2002;37(1):80-4.

68. Bernier MR. Perturbation and agility training in the rehabilitation of soccer athletes. Athletic Therapy Today. 2003;8(3):20-2

69. Noronha JC. Isometria na reconstrução do ligamento cruzado anterior. Porto: Universidade do Porto; 1999

70. Padua DA, Marshall SW. Evidence supporting ACL-injury-prevention exercise programs: a review of the literature. Athletic Therapy Today. 2006;11(2):11-23.

71. Cochrane JL, Lloyd DG, Besier TF, Ackland TS, Elliott BC, Ferguson DL. Training to reduce the risk of anterior cruciate ligament injury. J Sports Sci. 2004;22(6):586.

72. Devore P, Hagerman P. A Pregame Soccer Warm-up. Strength and Conditioning Journal. 2006;28(1):14-8 